DOI: https://doi.org/10.34883/PI.2021.11.6.004 УДК 618.177-089

Венцковский Б.М., Бурка О.А., Кущ В.М.

Национальный медицинский университет имени А.А. Богомольца, Киев, Украина

Ventskovsky B., Burka O., Kushch V.

Bogomolets National Medical University, Kyiv, Ukraine

\title{
Современные подходы к диагностике
}

и лечению женщин с наиболее

распространенными бактериальными

инфекциями, передающимися половым путем:

\author{
Current Approaches to the Diagnosis and Treatment of Women \\ with the Most Common Sexually Transmitted Bacterial Infections: \\ a Review of Evidence Recommendations 2021
}

Резюме

В статье представлены современные данные об эпидемиологических тенденциях, диагностике и лечении наиболее распространенных инфекций, передающихся половым путем (ИППП): хламидийной инфекции и гонореи. Анализ эпидемиологических и микробиологических исследований свидетельствует о значительном росте заболеваемости ИППП в странах с высоким уровнем экономического развития и необходимости постоянного пересмотра диагностических и лечебных подходов с учетом новых данных о физиологии возбудителей, механизмах и уровнях антибиотикорезистентности, а также возможностей лабораторной диагностики. В современных условиях клинические проявления ИППП все больше теряют типичные симптомы. Это создает необходимость лабораторного поиска всех распространенных возбудителей ИППП. Регулярные визиты женщин для скрининга рака шейки матки являются хорошей возможностью и для скрининга ИППП.

Таким образом, поскольку вакцины против распространенных бактериальных и протозойных возбудителей ИППП еще не разработаны, соблюдение гигиены полового поведения и своевременное выявление инфицированных при обследовании или скрининге с последующим этиопатогенетическим лечением являются основой системы борьбы с распространением ИППП и их последствий.

Ключевые слова: хламидийная инфекция, гонорея, полимеразная цепная реакция, культуральные методы, МАНК.

Abstract

The article presents modern data on epidemiological trends, diagnosis and treatment of the most common sexually transmitted infections (STIs): chlamydial infection and gonorrhea.

The analysis of epidemiological and microbiological studies indicates a significant increase in the incidence of STIs in countries with high economic development and the need for constant revision 
Современные подходы к диагностике и лечению женщин с наиболее распространенными бактериальными инфекциями, передающимися половым путем: обзор доказательных рекомендаций 2021 года

of diagnostic and treatment approaches, taking into account new data on the physiology of pathogens, mechanisms and levels of antibiotic resistance, as well as the possibilities of laboratory diagnostics.

In modern conditions, the clinical manifestations of STIs are increasingly losing their typical features. This creates the need for a laboratory search for all common STIs in the region. Regular visits of women for cervical cancer screening is a good opportunity to screen for STIs.

Thus, since vaccines against common bacterial and protozoal STI pathogens have not yet been developed, the promotion of hygiene of sexual behavior and the timely detection of infected persons during examination or screening with subsequent etiopathogenetic treatment form the basis of the system for combating the spread of STIs and their consequences.

Keywords: chlamydial infection, gonorrhea, polymerase chain reaction, culture methods, NAAT.

\section{- ВВЕДЕНИЕ}

Инфекции, передающиеся половым путем (ИППП), являются основной проблемой здравоохранения. Приблизительно 50\% всех новых ИППП встречаются у пациентов в возрасте от 15 до 24 лет, что составляет около $25 \%$ сексуально активных девушек-подростков [1]. ИППП часто протекают бессимптомно и могут привести к разным осложнениям. В 2021 г. были опубликованы основанные на доказательствах рекомендации центров по контролю за заболеваемостью (CDC), в 2020 г. вышли Канадские рекомендации по ИППП и Руководство Британской ассоциации сексуального здоровья и ВИЧ по профилактике, скринингу, диагностике и лечению ИППП $[2,4]$. Учитывая бессимптомное течение ИППП, много внимания уделяется скринингу, непосредственной целью которого является выявление и лечение инфицированных для предотвращения развития осложнений, а также выявление, тестирование и лечение их половых партнеров для предотвращения передачи и повторного заражения. Оперативная группа по профилактическим услугам США (USPSTF) выпустила рекомендации по скринингу на различные ИППП [5].

Некоторые ИППП чрезвычайно актуальны в контексте развития воспалительных заболеваний органов малого таза (ВЗОМТ), бесплодия и стремительного развития антибиотикорезистентности. Хламидиоз является самой распространенной бактериальной ИППП, о которой сообщают в США. Поскольку многие люди с хламидийной инфекцией могут иметь минимальные симптомы или вообще не иметь их, фактическое количество ежегодных инфекций значительно выше, чем число зарегистрированных случаев. К наиболее серьезным последствиям инфицирования C. trachomatis среди женщин относятся пельвиоперитонит, внематочная беременность, бесплодие [6]. Гонорея является второй по распространенности бактериальной ИППП в США и является основной проблемой общественного здоровья.

Целью данного обзора является систематизация современных подходов к диагностике и врачебной тактике при наиболее распространенных бактериальных ИППП, которые вызывают ВЗОМТ и приводят к бесплодию.

Скорость передачи C. trachomatis за половой акт составляет примерно 10\% между партнерами, при этом трансмиссия инфекции при 
ректальном и орофарингеальном акте неизвестна $[7,8]$. Передача C. trachomatis также может происходить от матери к ребенку из-за контакта младенца с половыми путями матери во время рождения. Среди матерей с нелеченой хламидийной инфекцией скорость передачи новорожденному оценивается примерно в $50 \%$.

Риск заражения C. trachomatis у младенца, рожденного через естественные родовые пути от женщины с хламидийным цервицитом, составляет примерно 50\%, по другим данным, может достигать 60-70\% [9]. Риск передачи инфекции от мужчины к женщине составляет примерно 50-70\% за один контакт с незначительными признаками повышения риска при большем сексуальном контакте, в то время как риск передачи N. gonorrhoeae от инфицированной женщины к ее партнеру-мужчине составляет примерно 20\% за один эпизод вагинального полового акта и повышается до 60-80\% после 4 или более контактов [10].

\section{Почему нужно проводить диагностику C. trachomatis и N. gonorrhoeae?}

Хламидиоз и гонорея - ВЗОМТ - являются прежде всего заболеваниями сексуально активных женщин. Основными объектами лечения должны быть два важнейших микроорганизма, передающихся половым путем, ассоциированные с острым В3ОМТ, - C. trachomatis и N. gonorrhoeae.

Из-за высокой чувствительности, специфичности и широкой доступности тестирование амплификации нуклеиновой кислоты (NAAT), состоящее из амплификации последовательностей ДНК или РНК с помощью полимеразной цепной реакции (ПЦР), является диагностическим методом выбора для диагностики хламидиоза и гонореи. Это исследование можно проводить на легкодоступных образцах, таких как вагинальные мазки, собранные самостоятельно пациенткой, врачом, или моча. Все чаще пациенты предпочитают самостоятельно собранные вагинальные мазки или скрининг на основе мочи перед более инвазивными образцами эндоцервикального или уретрального мазков. Моча - образец выбора для мужчин, является эффективным альтернативным типом образца для женщин [1, 2].

Возбудители, передающиеся половым путем, включая C. trachomatis, Trichomonas vaginalis и Mycoplasma genitalium, а также вирус простого герпеса (ВПГ) и сифилис, могут вызвать инфекции, подобные N. gonorrhoeae, поэтому их определение позволяет правильно подобрать тактику лечения [1].

Несмотря на то что лучшим методом диагностики N. gonorrhoeae является NAAT влагалищного мазка, забранного самостоятельно пациентом или клиницистом, эндоцервикальный мазок является не менее подходящим альтернативным образцом для NAAT, если исследование в зеркалах уже проводится.

Лекарственная стойкость является постоянной проблемой в терапии гонококковых инфекций. Например, распространенность резистентности к фторхинолонам у N. gonorrhoeae достигает почти 100\% в некоторых регионах и эти средства больше не рекомендуются для лечения инфекций N. gonorrhoeae [11]. Поэтому для микробиологической диагностики инфекции N. gonorrhoeae культура остается важным 
Современные подходы к диагностике и лечению женщин с наиболее распространенными бактериальными инфекциями, передающимися половым путем: обзор доказательных рекомендаций 2021 года

\section{Хламидиоз и гонорея: рекомендации скрининга в женской популяции}

C. trachomatis and N. gonorrhoeae screening recommendations by women population

\begin{tabular}{|c|c|c|c|}
\hline Популяция & $\begin{array}{l}\text { Рутинный скри- } \\
\text { нинг }\end{array}$ & Частота скрининга & $\begin{array}{l}\text { Дополнительные рекомендации } \\
\text { и комментарии к скринингу }\end{array}$ \\
\hline \multirow{2}{*}{ Возраст <25 лет } & C. trachomatis & Ежегодно & \multirow{4}{*}{$\begin{array}{l}\text { Скрининг на Trichomonas v. } \\
\text { при повышенном риске: } \\
\text { - новый половой партнер в течение } \\
3 \text { последних месяцев; } \\
\text { - больше одного полового партнера; } \\
\text { - наличие ИППП в прошлом; } \\
\text { - половой партнер с ИППП }\end{array}$} \\
\hline & N. gonorrhoeae & Ежегодно & \\
\hline Возраст >25 лет & $\begin{array}{l}\text { C. trachomatis, } \\
\text { N. gonorrhoeae }\end{array}$ & $\begin{array}{l}\text { При повышенном } \\
\text { риске }\end{array}$ & \\
\hline Беременные & $\begin{array}{l}\text { C. trachomatis, } \\
\text { N. gonorrhoeae }\end{array}$ & $\begin{array}{l}\text { В 1-м триместре, } \\
\text { если <25 лет и повы- } \\
\text { шенный риск }\end{array}$ & \\
\hline $\begin{array}{l}\text { ВИЧ- } \\
\text { инфицированные }\end{array}$ & $\begin{array}{l}\text { C. trachomatis, } \\
\text { N. gonorrhoeae, } \\
\text { Trichomonas } \\
\text { vaginalis }\end{array}$ & Ежегодно & \\
\hline
\end{tabular}

диагностическим инструментом при подозрении на резистентность к антибиотикам.

Рекомендации по обследованию женщин на наиболее распространенные бактериальные инфекции представлены согласно последнему руководству Sexually Transmitted Infections Treatment Guidelines, 2021 $[1,2]$ (см. таблицу).

\section{Особенности современных подходов к лечению C. trachomatis и N. gonorrhoeae}

Лиц, у которых были диагностированы хламидиоз или гонорея, необходимо проверить на другие инфекции, которые передаются половым путем, среди них ВИЧ и сифилис [2].

В 2019 г. В отчете CDC по угрозе антибиотикорезистентности N. gonorrhoeae была отнесена к 5 ургентным угрозам [12]. Особую обеспокоенность вызывает появление штаммов N. gonorrhoeae, продуцирующих бета-лактамазы расширенного спектра, и резистентных к современным макролидам штаммов [12].

Согласно обновленным рекомендациям CDC в 2020 г. были разработаны новые рекомендации по лечению гонореи [2].

Рекомендуемая схема лечения неосложненной гонококковой инфекции - инфекции шейки матки, уретры, прямой кишки у взрослых и подростков*: цефтриаксон 500 мг внутримышечно в разовой дозе для лиц с массой тела <150 кг. Лицам с массой тела $\geq 150$ кг следует ввести 1 г цефтриаксона.

Альтернативная схема, если цефтриаксон недоступен: гентамицин 240 мг внутривенно однократно плюс азитромицин 2 г перорально за один прием или цефиксим 800 мг перорально за один прием.

Лицам, проходящим лечение от хламидиоза, с целью снижения рисков передачи заболевания половым партнерам рекомендуют воздержаться от половых контактов в течение 7 дней после однократной

* Если хламидийная инфекция не была исключена, врачи обязаны лечить хламидиоз доксициклином по 100 мг внутрь 2 раза в сутки в течение 7 дней. 
терапии или до завершения 7-дневного режима лечения и исчезновения симптомов, если они были [2].

Согласно обновленным рекомендациям CDC [2] рекомендованная схема лечения хламидийной инфекции у взрослых и подростков: доксициклин по 100 мг внутрь 2 раза в сутки в течение 7 дней.

Альтернативная схема: азитромицин 1 г перорально за один прием или левофлоксацин 500 мг перорально 1 раз в сутки в течение 7 дней.

\section{- ВЫВОДЫ}

Регулярные визиты женщин для проведения скрининга рака шейки матки являются хорошей возможностью для проведения скрининга на ИППП.

В современных условиях клинические проявления ИППП теряют свои типичные признаки, что создает необходимость лабораторного поиска всех распространенных в данном регионе ИППП. Знание об этиологическом факторе воспалительного процесса позволяет выбрать правильную тактику антибиотикотерапии и предотвратить дальнейшее развитие антибиотикорезистентности.

Конфликт интересов. Авторы заявляют об отсутствии конфликта интересов.

Conflict of interest. The authors declare no conflict of interest.

\section{- ЛИТЕPATУPA/REFERENCES}

1. (2021) CDC. Sexually transmitted disease surveillance 2019. Atlanta GA: US Department of Health and Human Services. Available at: https://www. cdc.gov/std/statistics/2019/default.htm.

2. CDC. Sexually Transmitted Infections Treatment Guidelines, 2021

3. Public Health Agency of Canada. Canadian guidelines on sexually transmitted infections. Available at: http://www.phac-aspc.gc.ca/std-mts/sti-its/ (accessed 6 January 2020).

4. British Association for Sexual Health and HIV. Guidelines. Available at: http://www.bashh.org/BASHH/Guidelines/Guidelines/BASHH/Guidelines/ Guidelines.aspx (accessed 6 January 2020).

5. Davidson K.W., Barry M.J., Mangione C.M., Cabana M., Caughey A.B., Davis E.M., Donahue K.E., Doubeni C.A., Krist A.H., Kubik M., Li L., Ogedegbe G., Pbert L., Silverstein M., Simon M.A., Stevermer J., Tseng C.W., Wong J.B. (2021) Screening for Chlamydia and Gonorrhea: US Preventive Services Task Force Recommendation Statement. JAMA, no 26 (10), p. 949.

6. Workowski K.A., Bachmann L.H., Chan P.A. (2021) Sexually transmitted infections treatment guidelines, 2021. MMWR Recomm Rep., no 70 (No. RR-4), pp. 1-187.

7. Sexually Transmitted Infections National Strategic Plan for the United States:2021-2025. National Prevention Information Network. Connecting public health professionals with trusted information and each other (n.d.). Available at: https://npin.cdc.gov/publication/sexually-transmitted-infectionsnational-strategic-plan-united-states-2021-2025 (accessed 13 April 2021).

8. Althaus C.L., Turner K.M., Mercer C.H. (2014) Effectiveness and cost-effectiveness of traditional and new partner notification technologies for curable sexually transmitted infections: observational study, systematic reviews and mathematical modelling. Health Technol Assess., no 18, pp. 1-100, vii-viii.

9. Hammerscag M.R., Weisman L.E., Edwards M.S., Armsby C. (2021) Chlamydia trachomatis infections in the newborn. Literature review current through: Oct 2021.

10. Qureshi S., Chandrasekar P.H. (ed.) (2021) What causes sexually-transmitted gonorrhea? Medscape.

11. (2015) European Centre for Disease Prevention and Control. Gonococcal antimicrobial susceptibility surveillance in Europe, 2013. Stockholm: ECDC.12222

12. (2019) U. Centers for Disease Control, Antibiotic Resistance Threats in the United States (n.d.). doi: 10.15620/cdc:82532.

Подана/Submitted: 26.11.2021

Принята/Accepted: 06.12.2021

Контакты/Contacts: newlikar@ua.fm 